\title{
Fatty acid compositions, free radical scavenging activities, and antioxidative enzyme activities of high-preference and low-preference beef cuts of Hanwoo (Bos taurus coreanae) cows
}

\author{
Sang-Ho Moon ${ }^{1, a}$, Eun-Kyung Kim ${ }^{1, a}$, Se Young Jang ${ }^{2}$, Yujiao Tang ${ }^{3}$, Hye-Jin Seong ${ }^{1}$, \\ Yeong Sik Yun', Sanguk Chung ${ }^{1}$, and Mirae $\mathbf{O h}^{1,4, *}$
}

\author{
* Corresponding Author: Mirae Oh \\ Tel: +1-301-504-8450 Fax: +1-301-504-8465, \\ E-mail: korea100403@hanmail.net \\ ${ }^{1}$ Department of Food Bio Science, College of \\ Biomedical and Health science, Konkuk University, \\ Chungju 27478, Korea \\ 2 Institute of Livestock Environmental Management, \\ Daejeon 34068, Korea \\ ${ }^{3}$ School of Bio-sciences and Food Engineering, \\ Changchun University of Science and Technology, \\ Changchun 130600, China \\ ${ }^{4}$ Environmental Microbial and Food Safety Laboratory, \\ Agricultural Research Service, United States \\ Department of Agriculture, Beltsville, MD 20705, \\ USA \\ a These authors contributed equally to this work. \\ ORCID \\ Mirae Oh \\ https://orcid.org/0000-0002-6679-4101
}

Submitted Jan 19, 2018; Revised Apr 25, 2018; Accepted Jul 6, 2018
Objective: This study compared fatty acid compositions and antioxidant activities of highpreference cuts (loin, tenderloin, and rib) and low-preference cuts (brisket, topside, and shank) of Hanwoo (Bos taurus coreanae) cows to obtain potentially useful information for promoting the consumption of various low-preference cuts.

Methods: Individual $500 \mathrm{~g}$ samples of fresh beef were collected from each of the six cuts from 10 Hanwoo cows (quality grade 1) and immediately freeze-dried. The dried samples were evaluated for fatty acid composition, free radical scavenging activities (hydroxyl, alkyl, and 2, 2'-diphenyl-1-picrylhydrazyl [DPPH] radical), and antioxidative enzyme activities (glutathione peroxidase [GPx], glutathione-S-transferase [GST], and superoxide dismutase [SOD]). Results: The percentages of total polyunsaturated fatty acids were significantly higher in lowpreference cuts than in high-preference cuts $(\mathrm{p}<0.05)$. Hydroxyl, alkyl, and DPPH radical scavenging activities were significantly higher in low-preference cuts than in high-preference cuts $(\mathrm{p}<0.05)$. In addition, the activities of antioxidant enzymes, such as GPx, GST, and SOD, were significantly higher in low-preference cuts compared with high-preference cuts $(\mathrm{p}<0.05)$. Conclusion: These results may influence consumers to include more low-preference cuts in their selections based on the nutritional facts, which could help to balance the beef market in South Korea.

Keywords: Beef; Polyunsaturated Fatty Acid; Free Radical Scavenging Activity; Antioxidative Enzyme Activity; Hanwoo

\section{INTRODUCTION}

From 1995 to 2015, the annual per capita consumption of meat and beef in South Korea increased dramatically from $27.5 \mathrm{~kg}$ to $51.3 \mathrm{~kg}$ and $6.7 \mathrm{~kg}$ to $11.6 \mathrm{~kg}$, respectively [1]. Korean consumers prefer beef from native Korean Hanwoo cattle (Bos Taurus coreanae) over imported beef because they believe that Hanwoo beef has better flavor and marbling than imported beef, and they are accustomed to the taste of Hanwoo beef with its high levels of oleic acid and intramuscular fat [2,3]. In Korea, cattle carcasses are typically divided into 10 wholesale cuts: loin, tenderloin, rib, brisket, topside, shank, striploin, neck, blade, and rump [4]. Each cut has its own physicochemical properties such as taste, texture, and nutritional composition [5]. Fat content affects sensory traits such as texture, tenderness, juiciness, and flavor of beef, and consumer preferences depend on the sensory traits [6,7]. Consumer preference for various beef cuts is a major factor that affects market demand. Korean consumers generally prefer higher-fat cuts of beef over lower-fat cuts. This preference has caused the prices of high-preference cuts (HPCs) to increase well over double those of low-preference cuts 
(LPCs) [8]. Despite high prices for HPCs, the continuing demand for HPCs has led a market imbalance with an oversupply of LPC beef [9]. Thus, efforts to promote LPC consumption will help to increase the economic stability of the Korean beef market [9].

Along with flavor and appealing presentation, meat also must possess attributes of healthfulness, freshness, safety, functionality, and nutritional value in order to satisfy consumer preferences [10]. Health professionals worldwide have recommended decreasing overall consumption of saturated fatty acids (SFAs), trans-fatty acids, and cholesterol that cause obesity, cardiovascular diseases, and atherosclerosis, and increasing intake of $\omega-3$ polyunsaturated fatty acids (PUFAs) [11]. Thus, promoting meat with such characteristics would help effort to improve public health.

On the other hand, meats with more unsaturated fatty acids - especially those unsaturated fatty acids with more than two double bonds-are more rapidly oxidized than meats more SFAs [12]. Lipid oxidation in meat, which results in the production of free radicals, is related to meat quality attributes such as color, texture, flavor, and nutritional value $[13,14]$. Meat oxidation thus can lead to loss of nutritional value and reduced sensory quality [15]. There are several mechanisms in muscle tissue for counteracting oxidation, including endogenous enzymatic antioxidant systems such as glutathione peroxidase (GPx), glutathione-S-transferase (GST), and superoxide dismutase (SOD) [16]. So far, antioxidant activities have been studied in many materials. However, no studies have been performed where different cuts of beef with the same meat quality grade were compared for fatty acid compositions and antioxidant activities. To evaluate this, comparisons of HPCs and LPCs of beef were conducted using six beef cuts (loin, tenderloin, rib, brisket, topside, and shank) from Hanwoo (Bos taurus coreanae) cows.

\section{MATERIALS AND METHODS}

\section{Meat sample preparation}

Comparisons of HPCs and LPCs in this study used the same Hanwoo carcasses and samples used for the previously published study on beef chemical composition, free amino acid contents and antioxidant activity of beef [9]. Fresh samples from three HPCs (loin, tenderloin, rib) and three LPCs (brisket, topside, shank) of 10 Hanwoo (Bos taurus coreanae) cows (quality grade 1, medium marbled; carcass weight $365.7 \pm 20.8$ $\mathrm{kg}$, min $323 \mathrm{~kg}$ and $\max 395 \mathrm{~kg}$; slaughter age $57.2 \pm 10.7 \mathrm{mon}-$ ths, min 34 months and max 67 months) were purchased from a wholesale market. The 10 cows, grown on different farms with different diets, were slaughtered on the same day at the same local municipal slaughterhouse (Eumseong, Korea). The carcasses were evaluated one day after slaughter using the Hanwoo beef carcass grading system of the Korea Institute for Animal Products Quality Evaluation [4], and then divided into cuts and sent to the Sungin Co., Ltd. wholesale market (Seoul, Korea). Within any one category (e.g., all loin cuts or all shank cuts), each $500 \mathrm{~g}$ sample was selected as a region of muscle that included intramuscular fat from the same center part of every cut. The six muscles were $m$. longissimus dorsi (loin), m. psoas major (tenderloin), m. serratus ventralis (rib), m. rectus abdominis (brisket), m. semimembranosus (topside), and $m$. superficialis flexor (shank). The samples were transported by a cold-storage car from market to lab. Immediately after delivery, the samples from the sixty cuts of beef were dried using a lyophilizer (PVTFD 200R, Ilshin Lab Co.,Ltd., Seoul, Korea) at $-45^{\circ} \mathrm{C}(10 \mathrm{~mm}$ Torr for $72 \mathrm{~h})$ and then ground into powder form using a sample grinder (HMF-3100S, Hanil Co., Wonju, Korea).

\section{Fatty acid analysis}

To perform this experiment, total lipids from the meat samples were extracted using a chloroform:methanol mixture (2:1, $\mathrm{v}: \mathrm{v})$ including $0.01 \%$ butylated hydroxytoluene. The extracted lipids were dried using a rotary evaporator (N-110, Tokyo Rikakikai Co., Ltd, Tokyo, Japan) in vacuum and converted to methyl esters by base-catalyzed trans-esterification with sodium methoxide for $2 \mathrm{~h}$ at $30^{\circ} \mathrm{C}$ [17]. Fatty acid methyl esters (FAMEs) from meat samples were quantified using gas chromatography (GC-2010 Plus, Shimadzu, Tokyo, Japan) fused with silica capillary column (SPTM-2560, $100 \mathrm{~m} \times 0.25 \mathrm{~mm}$ i.d, 0.20- $\mu \mathrm{m}$ film thickness, Supelco, Bellefonte, PA, USA). Analysis was done using an initial isothermic period of $100^{\circ} \mathrm{C}$ for $4 \mathrm{~min}$, followed by a temperature increase at a rate of $3^{\circ} \mathrm{C} /$ min to $240^{\circ} \mathrm{C}$ and then an isothermic period of $240^{\circ} \mathrm{C}$ for 10 min. One microliter of FAMEs n-hexane was injected into the column. The injection port and detector were maintained at $225^{\circ} \mathrm{C}$ and $285^{\circ} \mathrm{C}$, respectively, with helium functioned gas. The components were identified by comparing the retention times of FAME peaks from samples with the standard (47885U, Supelco 37 Component FAME Mix, Supelco, USA). The compositions of individual fatty acids were first quantified as $\mathrm{mg}$ per $\mathrm{kg}$ of meat using the internal standard. Then, total fatty acid contents were expressed as g per $100 \mathrm{~g}$ of meat, while individual fatty acid compositions were expressed as a weight percentage of the total fatty acids.

\section{Free radical scavenging activity measurement}

Meat samples were homogenized in nine volumes of phosphate-buffered saline (PBS, pH 7.4; Gibco, Paisley, Scotland, $\mathrm{UK})$. The homogenates were centrifuged $\left(1,660 \mathrm{~g}\right.$ at $\left.4^{\circ} \mathrm{C}\right)$ for $30 \mathrm{~min}$; the supernatant was used for free radical scavenging activity assays with electron spin resonance (ESR) spectroscopy, which is a direct method of measuring production of free radicals.

Hydroxyl radical scavenging activity: Hydroxyl radical scav- 
enging activity was assayed by the method used by Rosen and Rauckman [18]. Hydroxyl radicals were generated via the ironcatalyzed Haber-Weiss reaction (Fenton-driven Haber-Weiss reaction), and the generated hydroxyl radicals rapidly reacted with nitrone spin-trap 5,5-dimethyl-1-pyrroline- $\mathrm{N}$-oxide (DMPO). The resultant DMPO-OH adduct was detectable with an ESR spectrometer. Thirty microliters of each sample was mixed with $30 \mu \mathrm{L}$ of DMPO $(0.3 \mathrm{M}), 30 \mu \mathrm{L}$ of $\mathrm{FeSO}_{4}$ $(10 \mathrm{mM})$, and $30 \mu \mathrm{L}$ of $\mathrm{H}_{2} \mathrm{O}_{2}(10 \mathrm{mM})$ in a phosphate buffer solution ( $\mathrm{pH}$ 7.2), and then transferred into a 100- $\mu \mathrm{L}$ Teflon capillary tube. After $2 \mathrm{~min} 30 \mathrm{~s}$, the ESR spectrum was recorded using an ESR spectrometer (JEOL Ltd., Tokyo, Japan). Experimental conditions were as follows: central field, 3,475 G; modulation frequency, $100 \mathrm{kHz}$; modulation amplitude, $2 \mathrm{G}$; microwave power, $1 \mathrm{~mW}$; gain, $6.3 \times 10^{5}$, and temperature, $298 \mathrm{~K}$.

Alkyl radical scavenging activity: Alkyl radical scavenging activity was measured by the method used by Hiramoto et al [19]. Alkyl radicals were generated by 2, 2'-azobis (2-amidinopropane) dihydrochloride (AAPH). Thirty microliters of each sample was mixed with $30 \mu \mathrm{L}$ of PBS (pH 7.4), $30 \mu \mathrm{L}$ of $40 \mathrm{mM}$ $\mathrm{AAPH}$, and $30 \mu \mathrm{L}$ of $40 \mathrm{mM}$ (4-pyridyl-1-oxide)-N-tert-butylnitrone. After incubation at $37^{\circ} \mathrm{C}$ in a water bath for $30 \mathrm{~min}$, the samples were transferred to a $100-\mu \mathrm{L}$ Teflon capillary tube. The spin adduct was recorded on an ESR spectrometer. Measurement conditions were as follows: central field, 3,475 G; modulation frequency, $100 \mathrm{kHz}$; modulation amplitude, $2 \mathrm{G}$; microwave power, $1 \mathrm{~mW}$; gain, $6.3 \times 10^{5}$, and temperature, $298 \mathrm{~K}$.

2, 2'-diphenyl-1-picrylhydrazyl radical scavenging activity: $\mathrm{DPPH}$ radical scavenging activity was measured using the method described by Nanjo et al [20]. Sixty microliters of each sample was added to $60 \mu \mathrm{L}$ of DPPH $(60 \mathrm{mM})$ in methanol solution. After mixing vigorously for $10 \mathrm{~s}$, the solution was transferred into a $100-\mu \mathrm{L}$ Teflon capillary tube, and the scavenging activity of each sample for the DPPH radical was measured using an ESR spectrometer. The spin adduct was measured on an ESR spectrometer exactly 2 min later. Experimental conditions were as follows: central field, 3,475 G; modulation frequency, $100 \mathrm{kHz}$; modulation amplitude, $2 \mathrm{G}$; microwave power, $5 \mathrm{~mW}$; gain, $6.3 \times 10^{5}$, and temperature, $298 \mathrm{~K}$.

\section{Antioxidative enzyme activity determination}

Meat samples were homogenized with ice-cold homogenizing buffer containing $50 \%$ potassium chloride, $1 \mathrm{M}$ Tris-hydrogen chloride, and $0.5 \mathrm{M}$ ethylenediaminetetraacetic acid (EDTA, $\mathrm{pH} 7.0)$ at $1: 10 \mathrm{w} / \mathrm{v}$ concentration. The homogenate was centrifuged $\left(1,660 \mathrm{~g}\right.$ at $\left.4^{\circ} \mathrm{C}\right)$ for $30 \mathrm{~min}$, and the supernatant was used for enzyme assays. Protein concentration was measured using the Biuret method described by Gornall et al [21].

Glutathione peroxidase activity: GPx activity was determined following the oxidation of nicotinamide adenine dinucleotide phosphate (NADPH) with t-butyl hydroperoxide as a substrate
[22]. The reaction mixture contained $2 \mathrm{mM}$ glutathione (GSH), $2 \mathrm{U}$ GSH reductase, $0.12 \mathrm{mM}$ NADPH, $0.5 \mathrm{mM}$ sodium azide, $0.2 \mathrm{mM} \mathrm{H}_{2} \mathrm{O}_{2}, 3 \mathrm{mM}$ cumene hydroperoxide, and $100 \mathrm{mM}$ phosphate buffer ( $\mathrm{pH}$ 7.5). The GPx activity was evaluated by monitoring the decrease in NADPH concentration at 340 $\mathrm{nm}$, and expressed as nmal GPx/min. mg protein.

Glutathione-S-transferase activity: The activity of GST toward 1-chloro-2,4-dinitrobenzene (CDNB) was determined using the method developed by Habig et al [23]. The approach was based on the reaction of CDNB with the -SH group of GSH, which was catalyzed by the GST contained in the samples. Here, $2 \mu \mathrm{L}$ of sample was reacted with $1 \mathrm{~mL}$ of the reaction mixture containing $1 \mathrm{mM} \mathrm{CDNB}, 1 \mathrm{mM} \mathrm{GSH}$, and $100 \mathrm{mM}$ phosphate buffer ( $\mathrm{pH}$ 7.5). Following conjugation of the thiol group of the GSH to the CDNB substrate, there was an increase in the absorbance at $340 \mathrm{~nm}$. The GST activity was expressed as $\mu \mathrm{mol} \mathrm{GSH} / \mathrm{min}$. mg protein.

Superoxide dismutase activity: SOD activity was estimated by the method described by Misra and Fridovich [24]. The samples were mixed with $1 \mathrm{M}$ xanthine, $0.2 \mathrm{mM}$ cytochrome, and $0.05 \mathrm{M}$ potassium cyanide in $0.05 \mathrm{M}$ potassium phosphate/0.1 mM EDTA buffer; and then xanthine oxidase was added to the reaction mixture. The SOD activity was measured from the inhibition of the reduction rate of cytochrome by superoxide radical as observed spectrophotometrically at $550 \mathrm{~nm}$. The SOD activity was expressed as inhibition rate percentage.

\section{Statistical analysis}

All analyses used ten samples for each of the six cut of beef. In addition, each assay was performed three times from the sample to ensure reproducibility. The results were expressed as the mean and standard error of the mean, and statistical analysis was performed by Duncan's multiple range test using SAS 9.3 (SAS Institute, Cary, NC, USA). The statistical significance was defined at $\mathrm{p}<0.05$.

\section{RESULTS AND DISCUSSION}

\section{Fatty acid compositions}

The fatty acid compositions of the HPCs and LPCs from Hanwoo cows are presented in Table 1 . The total fatty acid contents of loin and tenderloin were nearly double those of topside and shank, and the total fatty acid content of HPCs was significantly higher than that of LPCs $(\mathrm{p}<0.05)$ (Table 1$)$. In addition, the compositions for most of the fatty acids were found to be significantly different among the six beef cuts $(\mathrm{p}<0.05)$ (Table 1). The percentages of total SFAs and total monounsaturated fatty acids (MUFAs) were significantly different among six beef cuts $(\mathrm{p}<0.05)$ (Table 1$)$. The percentages of total PUFAs were significantly higher in LPCs than in HPCs $(\mathrm{p}<0.05)$ (Table 1$)$. SFAs have hypercholesterolemic properties that are consid- 
Table 1. Fatty acid compositions of high-preference and low-preference beef cuts from Hanwoo cows $(n=10)$

\begin{tabular}{|c|c|c|c|c|c|c|c|c|}
\hline \multirow{2}{*}{$\begin{array}{l}\text { Fatty acid } \\
\text { (\% total fatty acid) }\end{array}$} & \multicolumn{3}{|c|}{ HPCs } & \multicolumn{3}{|c|}{ LPCs } & \multirow{2}{*}{ SEM } & \multirow{2}{*}{$\mathrm{p}$-value } \\
\hline & Loin & Tenderloin & Rib & Brisket & Topside & Shank & & \\
\hline Capric acid (C10:0) & 0.01 & 0.01 & 0.00 & 0.00 & 0.00 & 0.00 & 0.01 & 0.411 \\
\hline Lauric acid (C12:0) & 0.07 & 0.07 & 0.04 & 0.02 & 0.01 & 0.04 & 0.03 & 0.240 \\
\hline Myristic acid (C14:0) & $3.33^{\mathrm{ab}}$ & $3.63^{\mathrm{a}}$ & $2.75^{b}$ & $2.72^{b}$ & $2.82^{b}$ & $3.00^{\mathrm{ab}}$ & 0.25 & 0.005 \\
\hline Pentadecanoic acid (C15:0) & 0.24 & 0.28 & 0.15 & 0.19 & 0.18 & 0.24 & 0.04 & 0.064 \\
\hline Palmitic acid (C16:0) & $27.00^{\mathrm{a}}$ & $27.11^{\mathrm{a}}$ & $22.02^{c}$ & $23.93^{b c}$ & $25.97^{\mathrm{ab}}$ & $25.20^{\mathrm{ab}}$ & 0.96 & $<0.001$ \\
\hline Heptadecanoic acid (C17:0) & 0.72 & 0.78 & 0.51 & 0.58 & 0.62 & 0.74 & 0.11 & 0.153 \\
\hline Stearic acid (C18:0) & 11.30 & 10.29 & 7.95 & 8.76 & 9.04 & 10.92 & 1.27 & 0.090 \\
\hline Arachidic acid (C20:0) & 0.04 & 0.04 & 0.01 & 0.01 & 0.00 & 0.05 & 0.03 & 0.547 \\
\hline SFAs (total) & $42.71^{\mathrm{a}}$ & $42.21^{\mathrm{ab}}$ & $33.45^{c}$ & $36.21^{b c}$ & $38.63^{b}$ & $40.19^{a b}$ & 1.91 & $<0.001$ \\
\hline Myristoleic acid (C14:1) & 1.10 & 1.10 & 1.65 & 1.34 & 1.25 & 0.96 & 0.22 & 0.074 \\
\hline Palmitoleic acid (C16:1) & $5.04^{b}$ & $5.16^{b}$ & $7.39^{\mathrm{a}}$ & $6.47^{\mathrm{ab}}$ & $6.19^{a b}$ & $5.14^{b}$ & 0.82 & 0.046 \\
\hline Heptadecenoic acid (C17:1) & 0.66 & 0.64 & 0.83 & 0.83 & 0.74 & 0.78 & 0.12 & 0.479 \\
\hline Elaidic acid (C18:1(t)) & 0.44 & 0.78 & 0.70 & 0.54 & 0.69 & 0.82 & 0.38 & 0.909 \\
\hline Oleic acid (C18:1(c)) & $47.75^{b}$ & $47.71^{b}$ & $53.26^{\mathrm{a}}$ & $51.45^{a b}$ & $49.64^{\mathrm{ab}}$ & $48.56^{b}$ & 1.26 & $<0.001$ \\
\hline Cis-11-Eicosenoic acid (C20:1) & 0.26 & 0.27 & 0.40 & 0.40 & 0.23 & 0.23 & 0.09 & 0.217 \\
\hline MUFAs (total) & $55.25^{b}$ & $55.66^{b}$ & $64.23^{\mathrm{a}}$ & $61.03^{\mathrm{ab}}$ & $58.74^{\mathrm{ab}}$ & $56.50^{b}$ & 1.89 & $<0.001$ \\
\hline Linolelaidic acid (C18:2(t)) ( $(-6)$ & 0.15 & 0.16 & 0.17 & 0.14 & 0.10 & 0.14 & 0.04 & 0.550 \\
\hline Linoleic acid (C18:2(c)) ( $\omega-6)$ & $1.31^{\mathrm{c}}$ & $1.42^{c}$ & $1.43^{c}$ & $1.75^{\mathrm{b}}$ & $1.78^{\mathrm{b}}$ & $2.29^{\mathrm{a}}$ & 0.13 & $<0.001$ \\
\hline Linolenic acid (C18:3) ( $\omega-3)$ & $0.05^{c}$ & $0.05^{c}$ & $0.06^{c}$ & $0.07^{b}$ & $0.07^{b}$ & $0.09^{\mathrm{a}}$ & 0.01 & $<0.001$ \\
\hline 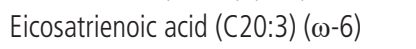 & $0.11^{\mathrm{ab}}$ & $0.09^{b}$ & $0.15^{\mathrm{ab}}$ & $0.21^{\mathrm{ab}}$ & $0.17^{\mathrm{ab}}$ & $0.23^{\mathrm{a}}$ & 0.05 & 0.041 \\
\hline PUFAs (total) & $1.63^{c}$ & $1.72^{c}$ & $1.80^{\circ}$ & $2.16^{\mathrm{b}}$ & $2.12^{b}$ & $2.74^{\mathrm{a}}$ & 0.17 & $<0.001$ \\
\hline$\omega-6$ & $1.58^{c}$ & $1.67^{c}$ & $1.74^{\mathrm{bc}}$ & $2.09^{b}$ & $2.05^{b}$ & $2.65^{\mathrm{a}}$ & 0.17 & $<0.001$ \\
\hline$\omega-3$ & $0.05^{c}$ & $0.05^{c}$ & $0.06^{\mathrm{bc}}$ & $0.07^{b}$ & $0.07^{b}$ & $0.09^{\mathrm{a}}$ & 0.01 & $<0.001$ \\
\hline MUFA/SFA & $1.31^{\mathrm{c}}$ & $1.36^{c}$ & $1.92^{\mathrm{a}}$ & $1.69^{\mathrm{b}}$ & $1.53^{\mathrm{bc}}$ & $1.41^{\mathrm{c}}$ & 0.12 & $<0.001$ \\
\hline PUFA/SFA & $0.04^{c}$ & $0.04^{c}$ & $0.05^{b}$ & $0.06^{\mathrm{a}}$ & $0.05^{b}$ & $0.07^{\mathrm{a}}$ & 0.01 & $<0.001$ \\
\hline$\omega-6 / \omega-3$ & 31.95 & 34.75 & 31.67 & 29.90 & 29.22 & 30.96 & 3.78 & 0.736 \\
\hline Total fatty acid (g per $100 \mathrm{~g}$ of meat) & 5.04 & 4.33 & 3.79 & 3.23 & 2.05 & 2.51 & 1.20 & 0.164 \\
\hline
\end{tabular}

SEM, standard error of the means; HPCs, high-preference cuts; LPCs, low-preference cuts; SFAs, saturated fatty acids (sum of C10:0, C12:0, C14:0, C15:0, C16:0, C17:0, $\mathrm{C} 18: 0$, and $\mathrm{C20}: 0)$; MUFAs, monounsaturated fatty acids (sum of C14:1, C16:1, C17:1, C18:1(t), C18:1(c), and C20:1); PUFAs, polyunsaturated fatty acids (sum of C18:2(t),

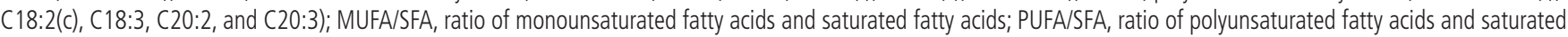
fatty acids; $\omega-6$, sum of C18:2(t), C18:2(C), C20:2, and C20:3; $\omega-3, C 18: 3 ; \omega-6 / \omega-3$, ratio of $\omega-6$ and $\omega-3$ fatty acids.

${ }^{a-d}$ Means in the same row with no superscript letters after them or with a common superscript letter are not significantly different $(p<0.05)$.

ered to be harmful to human health, whereas PUFAs can help prevent some human diseases, such as cancer, obesity, and cardiovascular diseases [25]. Since a higher ratio of PUFAs to SFAs is desirable for more healthful meat [12]. The meat composition ratio of SFAs to PUFAs could be used as an indicator for evaluating meat in terms of healthfulness.

\section{Free radical scavenging activities}

The hydroxyl, alkyl, and DPPH radical scavenging activities of the HPCs and LPCs from Hanwoo cows shown in Table 2. All radical scavenging activities of the meat samples occurred in a dose-dependent manner. Free radical scavenging activity was expressed as the $\mathrm{IC}_{50}$ value, which means $\mu \mathrm{g}$ per $\mathrm{mL}$ concentration of sample required for scavenging $50 \%$ of free radicals. During the experiment, the meat samples showed higher scavenging activities for the hydroxyl radicals than for other radicals indicating lower $\mathrm{IC}_{50}$ values. The hydroxyl radical scavenging activities in LPCs were significantly higher than

Table 2. Hydroxyl, Alkyl, and DPPH radical scavenging activities of high-preference and low-preference beef cuts from Hanwoo cows $(n=10)$

\begin{tabular}{|c|c|c|c|c|c|c|c|c|}
\hline \multirow{2}{*}{$\begin{array}{l}\text { Radical scavenging activity } \\
\quad\left(\mathrm{IC}_{50} \mu \mathrm{g} / \mathrm{mL}\right)\end{array}$} & \multicolumn{3}{|c|}{ HPCS } & \multicolumn{3}{|c|}{ LPCs } & \multirow{2}{*}{ SEM } & \multirow{2}{*}{ p-value } \\
\hline & Loin & Tenderloin & Rib & Brisket & Topside & Shank & & \\
\hline Hydroxyl & $679^{a}$ & $715^{a}$ & $606^{b}$ & $456^{c}$ & $452^{c}$ & $493^{c}$ & 4.09 & $<0.001$ \\
\hline Alkyl & $886^{a}$ & $753^{c}$ & $808^{b}$ & $621^{d}$ & $642^{d}$ & $526^{e}$ & 4.39 & $<0.001$ \\
\hline DPPH & $2,432^{b}$ & $2,589^{a}$ & $2,315^{b}$ & $1,962^{c}$ & $1,742^{d}$ & $1,862^{\text {cd }}$ & 12.35 & $<0.001$ \\
\hline
\end{tabular}

DPPH, 2,2'-diphenyl-1-picrylhydrazyl; HPCs, high-preference cuts; LPCs, low-preference cuts; SEM, standard error of the mean.

${ }^{a \cdot e}$ Means in the same row with no superscript letters after them or with a common superscript letter are not significantly different $(p<0.05)$. 
Table 3. GPx, GST, and SOD activities of high-preference and low-preference beef cuts from Hanwoo cows $(n=10)$

\begin{tabular}{|c|c|c|c|c|c|c|c|c|}
\hline \multirow{2}{*}{ Enzyme activity } & \multicolumn{3}{|c|}{ HPCs } & \multicolumn{3}{|c|}{ LPCs } & \multirow{2}{*}{ SEM } & \multirow{2}{*}{$\mathrm{p}$-value } \\
\hline & Loin & Tenderloin & Rib & Brisket & Topside & Shank & & \\
\hline GPx (mmoles/min. mg protein) & $1.05^{\mathrm{b}}$ & $1.02^{b}$ & $1.03^{b}$ & $1.37^{\mathrm{a}}$ & $1.39^{\mathrm{a}}$ & $1.40^{\mathrm{a}}$ & 0.01 & $<0.001$ \\
\hline GST ( $\mu$ moles/min. mg protein) & $20.46^{b}$ & $17.00^{c}$ & $19.88^{b}$ & $24.96^{\mathrm{a}}$ & $24.87^{\mathrm{a}}$ & $25.22^{\mathrm{a}}$ & 0.25 & $<0.001$ \\
\hline SOD (\% inhibition) & $88.36^{b}$ & $85.75^{b}$ & $85.58^{b}$ & $94.70^{\mathrm{a}}$ & $94.70^{\mathrm{a}}$ & $94.66^{\mathrm{a}}$ & 0.67 & $<0.001$ \\
\hline
\end{tabular}

GPx, glutathione peroxidase; GST, glutathione-S-transferase; SOD, superoxide dismutase; HPCs, high-preference cuts; LPCs, low-preference cuts; SEM, standard error of the means.

${ }^{a-c}$ Different superscript letters indicate significant differences among beef cuts within any row $(p<0.05)$.

those in HPCs $(p<0.05)$ (Table 2). The hydroxyl radical is one of the most reactive radicals produced from biological molecules, and it can damage living cells [26]. Moreover, LPC samples exhibited stronger alkyl radical scavenging activities than HPC samples $(\mathrm{p}<0.05)$ (Table 2). The DPPH radical scavenging activities of LPCs were also significantly higher than those of HPCs ( $\mathrm{p}<0.05$ ) (Table 2). DPPH, a stable free radical, has been generally used to measure the free radical scavenging capacity of various antioxidant substances [27]. Free radicals could be more prone to attack PUFAs [13]. The ratio of PUFAs to SFAs was higher in LPCs, but the amount of PUFAs was higher in HPCs (data not shown). This suggests that HPCs containing higher PUFA contents could be exposed to more free radicals, although a variety of other complex factors related to the production of and scavenging of free radicals should also be considered.

Cheong et al [28] reported $\mathrm{IC}_{50}$ values of hydroxyl, alkyl, and DPPH radical scavenging activity in Hanwoo steer loin (longissimus muscle) as 125,334 , and $172 \mu \mathrm{g} / \mathrm{mL}$, respectively; these values are higher than the findings of the present study. Although the free radical scavenging activities of the present study were lower than those reported by other researchers, the results show that free radical scavenging activities in LPCs were significantly higher than those in HPCs, providing positive information to support LPC consumption $(\mathrm{p}<0.05)$. More controlled studies will be needed to investigate antioxidant activities for meat samples of various cuts and sources since antioxidant activity may depend on an animal's sex, age, and feed.

\section{Antioxidative enzyme activities}

The antioxidative enzyme activities of the HPCs and LPCs from Hanwoo cows are presented in Table 3. All antioxidative enzyme (GPx, GST, and SOD) activities were significantly higher in LPC samples than in HPC samples $(\mathrm{p}<0.05)$ (Table 3). Oxidative reactions in meat leads to a loss of quality and nutrition factors [14]. Several antioxidant systems including endogenous enzymes such as GPx, GST, and SOD have been implicated in minimizing oxidation reactions in meat [16]. The endogenous enzymes are the primary antioxidant mechanism in vivo [29]. GPx reduces hydrogen peroxide and lipoperoxides formed form lipid oxidation [19]. SOD defends cells against reactive oxygen species and free radicals, and scavenges superoxide anion forming hydrogen peroxide $[13,16]$. The results of this study support the implication of these antioxidative enzymes in the protection against oxidative damages in beef.

In conclusion, these results support the idea that LPCs of beef such as brisket, topside, and shank have better ratios of PUFAs to SFAs and higher levels of antioxidant activities than HPCs such as loin, tenderloin, and rib; such information could be useful for health-conscious consumers when selecting from among available choices of beef. In addition to being useful nutritional information, the results reported here may provide an impetus for increasing overall consumption of lowpreference beef cuts, which could help to balance the beef market in South Korea.

\section{CONFLICT OF INTEREST}

We certify that there is no conflict of interest with any financial organization regarding the material discussed in the manuscript.

\section{ACKNOWLEDGMENTS}

This work was carried out with the support of the Cooperative Research Program for Agriculture Science \& Technology Development (Project No. PJ01275401), Rural Development Administration, Republic of Korea.

\section{REFERENCES}

1. Korea Meat Trade Association. Livestock trade statistics [Internet]. Gunpo, Korea: Korea Meat Trade Association; 2016 [cited 2016 May 1]. Available from: http://www.kmta.or.kr/html/ sub6-1.html? scode $=6$

2. Jung KK, Choi CB. Development of technologies to improve competitiveness of Hanwoo. In: Seoul Report to the Ministry of Agriculture; Seoul, Korea: Food and Rural Affairs; 2003. p. 85-98.

3. Kim LS, Lee SO, Kang SN, et al. The physiochemical, microbial and sensory characteristics of Hanwoo and imported chilled 
beef. Korean J Food Sci Anim Resour 1999;4:331-8.

4. Korea Institute for Animal Products Quality Evaluation. Korean carcass grading standard. Gunpo, Korea: Korea Institute for Animal Products Quality Evaluation; 2008.

5. Jo C, Cho SH, Chang J, Nam KC. Keys to production and processing of Hanwoo beef: a perspective of tradition and science. Anim Front 2012;2:32-8.

6. Troutt ES, Hunt MC, Johnson DE, et al. Chemical, physical, and sensory characterization of graound beef containing 5 to 30 percent fat. J Food Sci 1992;57:25-9.

7. Cho SH, Park BY, Kim JH, et al. Fatty acid profiles and sensory properties of Longissimus dorsi, Triceps brachii, and Semimembranosus muscles from Korean Hanwoo and Australian Angus beef. Asian-Australas J Anim Sci 2005;18:1786-93.

8. Korea Institute for Animal Products Quality Evaluation. 2015 Animal Products Grading Statistical Yearbook. Gunpo, Korea: Korea Institute for Animal Products Quality Evaluation; 2016.

9. Oh M, Kim EK, Jeon BT, et al. Chemical compositions, free amino acid contents and antioxidant activities of Hanwoo (Bos taurus coreanae) beef by cut. Meat Sci 2016;119:16-21.

10. Cho SH, Kim J, Park BY, et al. Assessment of meat quality properties and development of a palatability prediction model for Korean Hanwoo steer beef. Meat Sci 2010;86:236-242.

11. Daley CA, Abbott A, Doyle PS, et al. A review of fatty acid profiles and antioxidant content in grass-fed and grain-fed beef. Nutr J 2010;9:10-21.

12. Wood JD, Richardson RI, Nute GR, et al. Effects of fatty acids on meat quality: a review. Meat Sci 2003;66:21-32.

13. Gatellier P, Mercier Y, Renerre M. Effect of diet finishing mode (pasture or mixed diet) on antioxidant status of Charolais bovine meat. Meat Sci 2004;67:385-94.

14. Mercier Y, Gatellier P, Renerre M. Lipid and protein oxidation in vitro, and antioxidant potential in meat from Charolais cows finished on pasture or mixed diet. Meat Sci 2004;66:467-73.

15. Daun C, Johansson M, Onning G, Akesson B. Glutathione peroxidase activity, tissue and soluble selenium content in beef and pork in relation to meat ageing and pig RN phenotype. Food Chem 2001;73:313-9.

16. Pastsart U, Boever MD, Claeys E, Smet SD. Effect of muscle and post-mortem rate of $\mathrm{pH}$ and temperature fall on antioxidant enzyme activities in beef. Meat Sci 2013;93:681-6.
17. Qwele K, Hugo A, Oyedemi SO, et al. Chemical composition, fatty acid content and antioxidant potential of meat from goats supplemented with Moringa (Moringa oleifera) leaves, sunflower cake and grass hay. Meat Sci 2013;93:455-62.

18. Rosen GM, Rauckman EJ. Spin trapping of superoxide and hydroxyl radicals. Methods Enzymol 1984;105:198-205.

19. Hiramoto K, Johkoh H, Sako KI, Kikugawa K. DNA breaking activity of the carbon-centered radical generated from 2,2'azobis-(2-amidinopropane)-hydrochloride (AAPH). Free Radic Res Commun 1993;19:323-32.

20. Nanjo F, Goto K, Seto R, et al. Scavenging effects of tea catechins and their derivatives on 1,1-diphenyl-2-picrylhydrazyl radical. Free Radic Biol Med 1996;21:895-902.

21. Gornall A, Bradawill CG, David MM. Determination of serum proteins by means of biuret reaction. J Biol Chem 1949;77: 751-66.

22. Tamura M, Oschino N, Chance B. Some characteristics of hydrogen- and alkylhydroperoxides metabolizing systems in cardiac tissue. J Biochem 1982;92:1019-31.

23. Habig WH, Pubst MJ, Fleischner G, et al. The identity of glutathione S-transferase B with ligandin, a major binding protein of liver. Proc Natl Acad Sci USA 1974;71:3879-82.

24. Misra HP, Fridovich I. The role of superoxide anion in the autoxidation of epinephrine and a simple assay for superoxide dismutase. J Biochem 1972;247:3170-3175.

25. Gatellier P, Mercier Y, Juin H, Renerre M. Effect of finishing mode (pasture- or mixed-diet) on lipid composition, colour stability and lipid oxidation in meat from Charolais cattle. Meat Sci 2005;69:175-86.

26. Bergamini CM, Gambetti S, Dondi A, Cervellati C. Oxygen, reactive oxygen species and tissue damage. Curr Pharm Design 2004;10:1611-26.

27. Mandade R, Sreenivas S, Choudhury A. Radical scavenging and antioxidant activity of Carthamus tinctorius extracts. Free Radic Antioxid 2011;1:87-93.

28. Cheong SH, Kim KH, Jeon BT, et al. Effect of mulberry silage supplementation during late fattening stage of Hanwoo (Bos taurus coreanae) steer on antioxidative enzyme activity within the longissimus muscle. Anim Prod Sci 2012;52:240-7.

29. Halliwell B, Gutteridge JMC. Free radical in biology and medicine (2nd ed.). Oxfored, UK: Clarendon Press; 1989. 